\title{
Comparison of nutritional and nutraceutical properties of Chenopodium quinoa cultivated in Mexico and Ecuador
}

\author{
Magali Anabel Cañarejo-Antamba ${ }^{1}$, Oscar Bañuelos-Taváres ${ }^{2}$, Benito Reyes-Trejo ${ }^{1,3}$, \\ Teodoro Espinosa-Solares ${ }^{1}$, Vijay Joshi ${ }^{4}$, and Diana Guerra-Ramírez ${ }^{1,3^{*}}$ \\ 'Universidad Autónoma Chapingo, Posgrado en Ciencia y Tecnología Agroalimentaria, 56230, Texcoco, Edo. México, México. \\ ${ }^{2}$ Centro Internacional de Mejoramiento de Maíz y Trigo (CIMMYT), Tlaltizapan, 62770, Edo. Morelos, México. \\ ${ }^{3}$ Universidad Autónoma Chapingo, Laboratorio de Productos Naturales, Departamento de Preparatoria Agrícola, 56230, Texcoco, \\ Edo. México, México. *Corresponding author (dguerrar@chapingo.mx). \\ ${ }^{4}$ Texas A\&M University, Texas A\&M AgriLife Research Center, Uvalde, TX, 78801, USA.
}

Received: 25 February 2021; Accepted: 5 July 2021; doi:10.4067/S0718-58392021000400507

\begin{abstract}
Quinoa (Chenopodium quinoa Willd.) is considered a superfood due to its nutritional qualities and potential health benefits. In this work, the nutritional and nutraceutical properties were compared for white Ecuador quinoa seeds (WEQ) and red Ecuador quinoa seeds (REQ) with respect to the white Mexican quinoa seeds (WMxQ). Quinoa seeds from Peru have been introduced and adapted to the geographic and climatic conditions by the State of Morelos, Mexico, improved by mass selection in field to obtain plants with desirable phenotypic characteristics. The nutritional properties of seeds were evaluated through a proximate analysis, mineral content, amino acids profile, and fatty acid profile of quinoa oil. The nutraceutical properties were determined quantifying total phenols, total betalains and antioxidant capacity. The

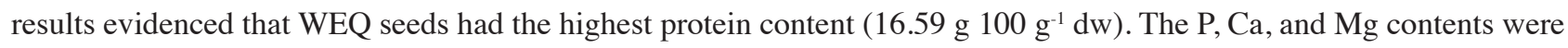
high in WMxQ (424.6, 60.3, and $152.3 \mathrm{mg} 100 \mathrm{~g}^{-1}$ in dw respectively). Arginine, glutamic acid, and alanine were the most abundant amino acids in the three cultivars. In all quinoas, unsaturated fatty acids were most predominant $(73.6 \%$ to $78.0 \%$ ). The Mexican quinoa seeds showed the highest total phenolic content ( $2.9 \mathrm{mg}$ gallic acid equivalent $\mathrm{g}^{-1}$ in $\mathrm{fw}$ ).

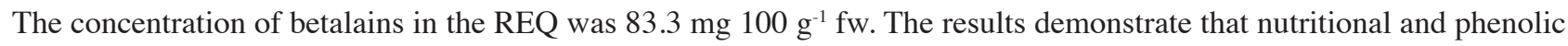
contents varies according to the color seeds and region. Quinoa of Mexico is high in phenolic compounds and may be used as a source of natural antioxidants.
\end{abstract}

Key words: Antioxidant capacity, betalains, free amino acids, nutraceutical potential, quinoa.

\section{INTRODUCTION}

Quinoa (Chenopodium quinoa Willd.), member of the Amaranthaceae family, is a native species of the Andean region in South America and routinely used in the preparation of soups, salads, desserts, and sweet drinks, among others (Ceyhun and Sanlier, 2019). Quinoa is mainly produced in Bolivia, Ecuador and Peru, but its cultivation has spread to others regions of Europe, Asia, and North America (Rojas et al., 2011). This species due to its wide genetic variability and broader adaptability grows from sea level until to an altitude of $4000 \mathrm{~m}$ and can tolerate adverse agro-ecological and edaphic conditions (Vega-Gálvez et al., 2010). In 1990, Peruvian quinoa was introduced in Mexico and has adapted to dry climate (Coahuila, $1300 \mathrm{~m}$ a.s.1.), sub-humid climate (State of Mexico, from 2300 to $2600 \mathrm{~m}$ a.s.1.), and humid subtropical climate (Morelos, $940 \mathrm{~m}$ a.s.l.) Quinoa that was adapted and produced in the State of Morelos shown higher yield of seeds $\left(2 \mathrm{tha}^{-1}\right)$ and higher forage production. 
Quinoa is considered a superfood due to its nutritional qualities (Maradini Filho et al., 2017), thus it is becoming increasingly popular choice of food among the health-conscious populations and millennials. Quinoa seeds are a rich source of protein (Lee and Sim, 2018), free sugars (Pereira et al., 2019), organic acids (Pellegrini et al., 2018), vitamins, minerals, and essential amino acids (Vilcacundo and Hernández-Ledesma, 2017). In addition to macronutrients, quinoa also contains bioactive compounds such as phenols and betalains responsible for the various seed colors and are related to the antioxidant capacity (Tang and Tsao, 2017). The nutritional composition and phenolic contents of quinoa seeds vary considerably according to the geographic location, environmental factors, soil type, fertilization, and genetic background (Miranda et al., 2011). A detailed landscape of the chemical composition of Morelos region adapted germplasm would better understand its nutraceutical properties, stability in response to Genotype $\times$ Environment interactions, and allow its exploitation through genetic improvement. Previous studies compared quinoas cultivated in Denmark, Poland, Chile, USA, Argentina, and Korea and reported high contents of proteins (from $12 \%$ to $16 \%$ ), lipids (from $4.2 \%$ to $13.0 \%$ ), and ash (from 2.7\% to 4.0\%) with respect to quinoas of Peruvian and Bolivian origin (Lee and Sim, 2018; Sobota et al., 2020). Although several studies have evaluated quinoa varieties grown in different parts of the world, little is known about the ones adapted to the Mexican environment.

Therefore, the aim of this study was to compare the nutritional and nutraceutical properties of three quinoa cultivars; one adapted in Mexico and the other two from the Andean region of Ecuador. The outcome of this study would contribute to the knowledge of the potential benefits of quinoa seeds to the health of consumers in these two regions of the world.

\section{MATERIAL AND METHODS}

\section{Plant materials}

White Ecuador quinoa (Chenopodium quinoa Willd.) seeds (WEQ) 'INIAP-Tunkahuan' released by Instituto Nacional de Investigaciones Agropecuarias de Ecuador (INIAP) were purchased directly from the farmers in Ibarra $\left(0^{\circ} 19^{\prime} 12^{\prime \prime} \mathrm{N}\right.$, 78 12'36" W), Imbabura Province, and red Ecuador quinoa seeds (REQ) 'red-INCA' were purchased in local market of Quito, Ecuador. White Mexico quinoa seeds (WMxQ), were provided by the Centro Internacional de Mejoramiento de Maíz y Trigo (CIMMYT), Experimental Station of Tlaltizapan (1841'19.8" N, 9907'35.1" W), Morelos, Mexico. The different quinoa samples were acquired in the same season year. In the case of Ecuador, the quinoa is grown in Highland soil with an annual rainfall from 200 to $500 \mathrm{~mm}$ and temperature from 13 to $18{ }^{\circ} \mathrm{C}$, while in Mexico, the quinoa was produced with low pluvial precipitation ( $<100 \mathrm{~mm}$ annual) and average temperature of $22{ }^{\circ} \mathrm{C}$. Seeds were washed, dried, and ground using a blender (NB-101S, Housewares, Los Angeles, California, USA) until obtaining a fine powder (20 mesh). Quinoa flours were stored in polyethylene bags at $-20^{\circ} \mathrm{C}$ until use. The color was measured in the whole seeds.

\section{Chemicals}

Folin-Ciocalteu phenolic reagent, anhydrous sodium carbonate, 2,2-diphenyl-1-picrylhydrazyl (DPPH), sodium acetate trihydrate, 2,4,6-tris(2-pyridyl)-s-triazine (TPTZ), ferric chloride hexahydrate, quercetin, potassium persulfate, and 6-hydroxy-2,5,7,8-tetramethylchromane-2-carboxylic acid (Trolox), gallic acid, 2,2-azino-bis(3-ethylbenzothiazoline-6sulfonic acid) (ABTS) were obtained from Sigma-Aldrich products (St. Louis, Missouri, USA). Aluminum chloride and potassium acetate were acquired from Fermont S.A. de C.V. and Meyer S.A. de C.V., Mexico, respectively. All reagent were analytical grade.

\section{Determination of color}

The color was determined with a Hunter lab colorimeter (MiniScan XE Plus 45/0-L, HunterLab, Reston, Virginia, USA) in CieLab scale $\left(L^{*}, a^{*}, b^{*}\right)$. Values of $a^{*}$ and $b^{*}$ were calculated, the tone angle (Hue; $\left.h^{*}\right)$ parameter and color saturation (Chroma; $\mathrm{C}^{*}$ ) applying the Equations 1 and 2, while the $\mathrm{L}^{*}$ value it was taken as lightness (McGuire, 1992):

$$
\begin{gathered}
h^{*}=\operatorname{Tan}^{-1} \frac{b^{*}}{a^{*}} \\
C^{*}=\sqrt{\left(a^{*}\right)^{2}+\left(b^{*}\right)^{2}}
\end{gathered}
$$




\section{Proximate and chemical analysis}

The proximate composition was determined according to the methods described by AOAC (1998), moisture (934.01), protein (2001.11, using $\mathrm{N} \times 6.25$ ), fiber (962.09), ash (942.05), and fat (920.39). Mineral content was determined as described by Gavlak et al. (2013) using a microwave (Microwave Reaction System, Anton Paar, Mexico). A quinoa flour sample $(0.15 \mathrm{~g})$ was placed in a microwave digestion tube and added $0.5 \mathrm{~mL}$ concentrated nitric acid $(16.8 \mathrm{~N})$ and $2.0 \mathrm{~mL}$ $30 \%$ hydrogen peroxide to each tube. The tubes with sample and reagents were taken to predigestion for 30 min and then placed in the microwave. An atomic absorption spectrophotometer (GBC, SavantAA, Mexico) was used to $\mathrm{Ca}, \mathrm{Mg}, \mathrm{Fe}$ and $\mathrm{Zn}$, a flame photometer (Lachat Instrument, Burlington, Canada) to K, and an ultra-violet spectrophotometer (Jenway, 6715 UV/Vis, Staffordshire, UK) to P.

\section{Free amino acids profile identification}

Free amino acids were analyzed according to the method proposed by Joshi et al. (2006). Quinoa seeds (10 $\mathrm{mg}$ ) were frozen in liquid nitrogen and ground to a fine powder after mixing with $20 \mathrm{mM} \mathrm{HCl}\left(10 \mu \mathrm{L} \mathrm{mg}^{-1}\right.$ sample), the mixtures were centrifuged at $14000 \times \mathrm{g}$ at $4{ }^{\circ} \mathrm{C}$ for $20 \mathrm{~min}$. The supernatants were derivatized using an AccQ-Fluor reagent kit (Waters, Milford, Massachusetts, USA). Free amino acids were carried out using UPLC system (Acquity H-class, Waters) coupled with Xevo TQ mass spectrometer using an electrospray ionization (ESI) probe. Samples $(10 \mu \mathrm{L})$ were injected on to column (AccQTag, $2.1 \mathrm{~mm}$ i.d. $\times 100 \mathrm{~mm}, 1.7$ particles, Waters) and the data were collected using Empower software (Waters). The mobile phase of water phase (A) $(0.1 \%$ formic acid $\mathrm{v} / \mathrm{v})$ and acetonitrile (B) $(0.1 \%$ formic acid $\mathrm{v} / \mathrm{v})$, with a stable flow rate at $0.5 \mathrm{~mL} \mathrm{~min}^{-1}$ and column temperature setting at $60^{\circ} \mathrm{C}$. L-Norleucine was used as an internal control, and the amino acids were quantified in $\mathrm{nmol} \mathrm{mg}^{-1}$ quinoa seeds.

\section{Fatty acid composition}

Quinoa flour samples $(20 \mathrm{~g})$ were subjected to extraction $(14 \mathrm{~h})$ with $n$-hexane in Soxhlet equipment. After, hexane was removed under reduced pressure in a rotary evaporator (R-300, Büchi, Flawil, Switzerland) to obtain the oil. Fatty acid methyl esters (FAME's) were obtained by esterification and transesterification of the oil (López-Yerena et al., 2018) with some modifications. The FAME's were analyzed in a gas chromatograph (6890, Agilent, Santa Clara, California, USA) with an ATSilar column $(0.25 \mathrm{~mm}$ i.d. $\times 30 \mathrm{~m} \times 0.25 \mu \mathrm{m}$ film thickness, Croydon, England), and a flame ionization detector (FID). The initial oven temperature was $170{ }^{\circ} \mathrm{C}$ with ramps of $10^{\circ} \mathrm{C}$ per min at a final temperature of $240{ }^{\circ} \mathrm{C}$. The injector and detector temperatures were set at $250{ }^{\circ} \mathrm{C}$ and hydrogen gas was used at a flow rate of $1.8 \mathrm{~mL} \mathrm{~min}^{-1}$. The results were expressed as a percentage of the area (\% area).

\section{Extraction and fractionation of samples}

A quinoa flour sample $(1.0 \mathrm{~g})$ was successively extracted with $25 \mathrm{~mL}$ methanol:water $(50: 50 \mathrm{v} / \mathrm{v}, \mathrm{pH} 2)$ and acetone:water $(70: 30, \mathrm{v} / \mathrm{v})$ solution. The extract was shaken at room temperature $\left(22^{\circ} \mathrm{C}\right)$ for $1 \mathrm{~h}$ and then centrifuged $(5810 \mathrm{R}$, Eppendorf, Hamburg, Germany) at $2100 \times \mathrm{g}$, at $4^{\circ} \mathrm{C}$ for $10 \mathrm{~min}$. The supernatants were mixed, filtered (ashless filter paper, Whatman grade 41 , GE Healthcare, Buckinghamshire, UK), adjusted to $50 \mathrm{~mL}$, and stored at $-18{ }^{\circ} \mathrm{C}$ until use. From this extract, the free phenolics, flavonoids, and antioxidant capacity were determined. The pellet obtained from the previous extractions was re-extracted with $10 \mathrm{~mL}$ methanol:concentrated sulfuric acid $(90: 10, \mathrm{v} / \mathrm{v})$ and refluxed for $10 \mathrm{~h}$, then centrifuged $\left(2100 \times \mathrm{g}, 4^{\circ} \mathrm{C}, 10 \mathrm{~min}\right)$. The supernatant was recovered and adjusted to $10 \mathrm{~mL}$ with the extraction solvent, filtered, and stored at $-18{ }^{\circ} \mathrm{C}$ until use. From this extract, the phenolics, flavonoids, betalains, and antioxidant capacity were determined (Abderrahim et al., 2015).

\section{Total phenolics, flavonoids, and betalains content}

The total phenolic content (TPC) quantification was carried out according to Hernández-Rodríguez et al. (2016) using Folin-Ciocalteu reagent. A gallic acid standard curve with a linear range (concentration 0.00 to $0.01 \mathrm{mg}$ gallic acid $\mathrm{mL}^{-1}$ ) was prepared. Results were expressed as $\mathrm{mg}$ gallic acid equivalent (GAE) $\mathrm{g}^{-1}$ quinoa flour.

The total flavonoids content (TFC) was determined according to the method described by Chang et al. (2002). A quercetin standard curve with a linear range (concentration 0 to $0.01 \mathrm{mg}$ quercetin $\mathrm{mL}^{-1}$ ) was prepared. The results were expressed as mg quercetin equivalent $(\mathrm{QE}) \mathrm{g}^{-1}$ quinoa flour. 
Total betalains were quantified by the method of Castellanos-Santiago and Yahia (2008) adapted to the microplates. Total betalains content $(\mathrm{BC})$ was calculated from the equation:

\section{$\mathrm{BC}\left(\mathrm{mg} \mathrm{g}^{-1}\right)=[(\mathrm{A} \times \mathrm{DF} \times \mathrm{MW} \times \mathrm{Vd}) / \varepsilon \times \mathrm{L} \times \mathrm{Wd}]$}

where $\mathrm{A}$ is the maximum absorbance at 535 and $435 \mathrm{~nm}$ for betacyanins and betaxanthin respectively, DF is the dilution factor, $\mathrm{MW}\left(\mathrm{g} \mathrm{mol}^{-1}\right)$ is molecular weight of betaxanthin $\left(308 \mathrm{~g} \mathrm{~mol}^{-1}\right)$ and betacyanin $\left(550 \mathrm{~g} \mathrm{~mol}^{-1}\right), \mathrm{Vd}(\mathrm{mL})$ is volume of sample capacity, $\varepsilon$ is molar extinction coefficient of betacyanins $\left(\varepsilon=60000 \mathrm{~L} \mathrm{~mol}^{-1} \mathrm{~cm}^{-1}\right)$ and betaxanthin $(\varepsilon=48000$ $\left.\mathrm{L} \mathrm{mol}^{-1} \mathrm{~cm}^{-1}\right), \mathrm{L}(\mathrm{cm})$ is length of the path-light in the well $(0.50 \mathrm{~cm})$ and $\mathrm{Wd}(\mathrm{g})$ is sample weight. The absorbances were measured in a Microplate reader (software Gen5, Biotek Instruments Inc., Winooski, Vermont, USA). The results were expressed as mg betalain $100 \mathrm{~g}^{-1}$ quinoa flour.

\section{Antioxidant capacity}

The antioxidant capacity (AC) of the extract was determined by 2,2-azino-bis(3-ethylbenzothiazoline-6-sulfonic acid) (ABTS) (Re et al., 1999), ferric reducing antioxidant power (FRAP) (Benzie and Strain, 1996) and 2,2-diphenyl-1picrylhydrazyl (DPPH) (Cheng et al., 2006) assays, adapted to the microplates. The results were expressed as mg trolox equivalent (TE) $\mathrm{g}^{-1}$ quinoa flour. The inhibitory concentration $50 \%\left(\mathrm{CI}_{50}\right)$ was calculated by plotting the percentages of degraded DPPH against the sample concentration.

\section{Statistical analysis}

Results are presented as mean value \pm standard deviation of three replicates per sample and analyzed by one-way ANOVA. To compare means Tukey's test was used and differences were considered significant at $p \leq 0.05$. Statistical analysis was performed using SAS program 2005 (SAS Institute, Cary, North Carolina, USA).

\section{RESULTS AND DISCUSSION}

\section{Color study}

Figure 1 shows the color parameters $\mathrm{L}^{*}, \mathrm{a}^{*}$ and $\mathrm{b}^{*}$ of three quinoa cultivars. The results evidenced positive values for $a^{*}$ and $b^{*}$ coordinates. The lightness value $\left(\mathrm{L}^{*}\right)$ that indicates color brilliance revealed a significant difference $(\mathrm{P} \leq 0.05)$ between quinoa cultivars. The positive $\mathrm{a}^{*}$ coordinate was higher in the red seeds based on the value of hue $\left(40.81^{\circ}\right)$ and chroma (16.22), also showed a significant difference $(\mathrm{P} \leq 0.05)$, the tone of this seeds was purple-red, less pure, and less bright. The $\mathrm{b}^{*}$ positive coordinate was high in the WMxQ cultivar, according to the hue $\left(76.26^{\circ}\right)$ and chroma (27.33) values which were significantly different $(\mathrm{P} \leq 0.05)$ between the studied cultivars. The combination of these coordinates

Figure 1. Graphical representation of color parameters $L^{*}, a^{*}$, and $b^{*}$ of three quinoa cultivars $(n=3)$.

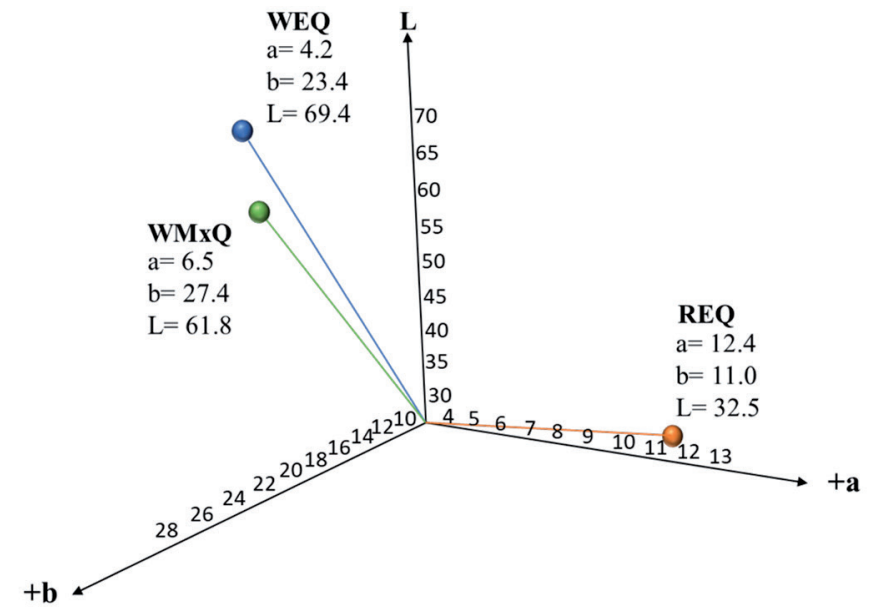

WMxQ: White Mexico quinoa; WEQ: white Ecuador quinoa; REQ: red Ecuador quinoa; L*: lightness (\%); +a: x, red-purple tone component; $+\mathrm{b}$ : y, yellow tone component. 
with the L value revealed the yellow-cream shade slightly lighter but with less lightness than the WEQ. Pellegrini et al. (2018) reported a hue of $89.71^{\circ}$ and chroma of 16.69 in white quinoas, in this study, the hue value was low while the chroma value was higher than found by these authors. The L value* in red quinoa was lower than values reported by Laqui-Vilca et al. (2018), who obtained values for lightness between $48.1 \%$ and $53.5 \%$ in red quinoa seeds pericarp. The food color is an indicator of natural pigments, these pigments can be used as food coloring and be considered as functional ingredients due to their implication in human health (Shetty and Geethalekshmi, 2017). The color of quinoa seeds varies from white to black with yellow, red, pink, and violet hues. Red quinoa have significant betalains content; in particular of betanins and isobetanins that are pigments with biological activities for the benefit of health (Tang et al., 2015).

\section{Proximate and chemical analysis}

Quinoa, with high nutritional potential, is a species of $\mathrm{C}_{3}$ photosynthetic pathway, unlike other cereals, it adapts and tolerates agroclimatic changes (García-Parra et al., 2020). The content of protein, essential amino acids, fiber, carbohydrates, and unsaturated fatty acids determines the nutritional quality of quinoa seeds. The chemical and proximate composition of

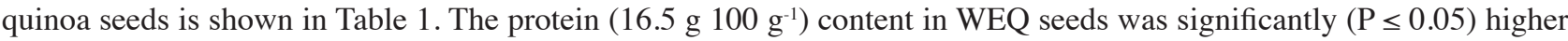

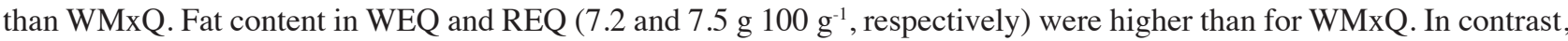

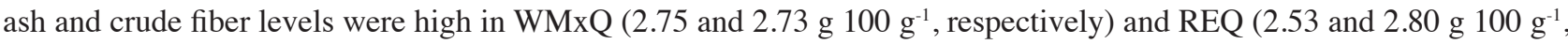

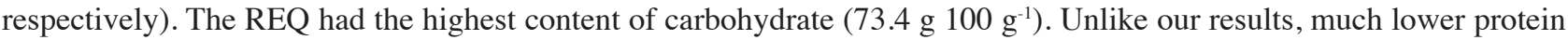

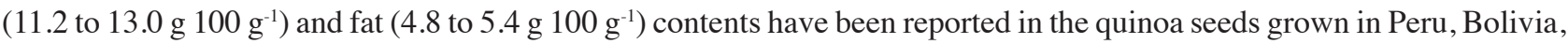
and Spain (Nowak et al., 2016; Pellegrini et al., 2018; Pereira et al., 2019). Protein content in the range of $13 \%$ to $17 \%$ has been reported by most studies (Maradini Filho et al., 2017). This content in quinoa seeds is higher than in traditional cereals such as wheat $(7.4 \%)$, barley $(10.5 \%)$, and rice (13.3\%) (Tang and Tsao, 2017) and is considered a high-quality protein because provide all essential amino acids, particularly by the presence of lysine, methionine, and threonine, which are lacking in other cereals such as wheat and corn (Hernández-Ledesma, 2019). The consumption of $100 \mathrm{~g}$ quinoa seeds accounts for $46.5 \%$ of daily protein requirement according to Food and Agriculture Organization of the United Nations (FAO) guidelines. Furthermore, the quinoa contains important bioactive compounds as peptides and phenolic compounds that are related to the prevention of cardiovascular and immunological diseases, cancer, diabetes, among many others (Tang and Tsao, 2017). The Highland Northern of Ecuador soils are of volcanic origin and contain significant amounts of organic matter, a source of available $\mathrm{N}$ for the plants (Huygens et al., 2008) by this reason the Ecuadorian seeds contain the highest concentration of protein. Additionally, oil and crude protein contents is affected by Genotype $\times$ Environment interaction (Arslanoglu et al., 2011).

Table 1. Proximate analysis and mineral content of three quinoa cultivars.

\begin{tabular}{lrrr}
\hline & \multicolumn{1}{c}{ WMxQ } & \multicolumn{1}{c}{ WEQ } & \multicolumn{1}{c}{ REQ } \\
\hline Moisture & $7.39 \pm 0.18 \mathrm{a}$ & $6.99 \pm 0.02 \mathrm{~b}$ & $7.10 \pm 0.02 \mathrm{ab}$ \\
Protein & $15.74 \pm 0.03 \mathrm{~b}$ & $16.59 \pm 0.12 \mathrm{a}$ & $13.70 \pm 0.04 \mathrm{c}$ \\
Fat & $6.53 \pm 0.10 \mathrm{~b}$ & $7.26 \pm 0.12 \mathrm{a}$ & $7.52 \pm 0.18 \mathrm{a}$ \\
Ash & $2.75 \pm 0.04 \mathrm{a}$ & $2.25 \pm 0.22 \mathrm{~b}$ & $2.53 \pm 0.03 \mathrm{ab}$ \\
Crude fiber & $2.73 \pm 0.05 \mathrm{a}$ & $1.64 \pm 0.24 \mathrm{~b}$ & $2.80 \pm 0.08 \mathrm{a}$ \\
Carbohydrate & $72.23 \pm 0.13 \mathrm{~b}$ & $72.25 \pm 0.08 \mathrm{~b}$ & $73.43 \pm 0.07 \mathrm{a}$ \\
$\mathrm{P}$ & $424.66 \pm 18.9 \mathrm{a}$ & $296.33 \pm 9.29 \mathrm{~b}$ & $235.66 \pm 5.13 \mathrm{c}$ \\
$\mathrm{K}$ & $254.66 \pm 2.52 \mathrm{~b}$ & $241.66 \pm 4.72 \mathrm{c}$ & $334.66 \pm 6.81 \mathrm{a}$ \\
$\mathrm{Ca}$ & $60.33 \pm 3.21 \mathrm{a}$ & $21.00 \pm 1.00 \mathrm{~b}$ & $14.66 \pm 1.52 \mathrm{c}$ \\
$\mathrm{Mg}$ & $152.33 \pm 4.04 \mathrm{a}$ & $124.33 \pm 3.05 \mathrm{~b}$ & $97.66 \pm 2.52 \mathrm{c}$ \\
$\mathrm{Fe}$ & $3.97 \pm 0.11 \mathrm{~b}$ & $4.78 \pm 0.11 \mathrm{a}$ & $3.85 \pm 0.05 \mathrm{~b}$ \\
$\mathrm{Zn}$ & $2.08 \pm 0.06 \mathrm{~b}$ & $2.52 \pm 0.19 \mathrm{a}$ & $2.07 \pm 0.00 \mathrm{~b}$ \\
\hline
\end{tabular}

Moisture content is expressed as $\mathrm{g} 100 \mathrm{~g}^{-1}$ fresh weight; protein, fat, ash, crude fiber, and carbohydrate contents are expressed as g $100 \mathrm{~g}^{-1}$ dry weight; minerals content are expressed as $\mathrm{mg} 100 \mathrm{~g} \mathrm{~g}^{-1}$ dry weight. For each row, means \pm standard deviation followed by different letters are significantly different $(n=3, P \leq 0.05)$.

WMxQ: White Mexico quinoa; WEQ: white Ecuador quinoa; REQ: red Ecuador quinoa. 
According to our results, $\mathrm{P}$ was the main micronutrient in all the analyzed samples (235.6-424.6 $\left.\mathrm{mg} 100 \mathrm{~g}^{-1}\right)$, followed

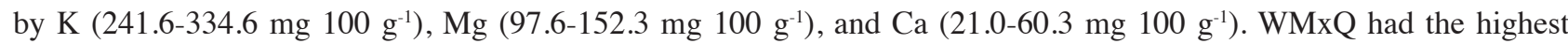
contents of $\mathrm{P}$, Ca, and Mg; WEQ had the highest contents of Fe $\left(4.7 \mathrm{mg} 100 \mathrm{~g}^{-1}\right)$ and $\mathrm{Zn}\left(2.4 \mathrm{mg} 100 \mathrm{~g} \mathrm{~g}^{-1}\right)$, showing

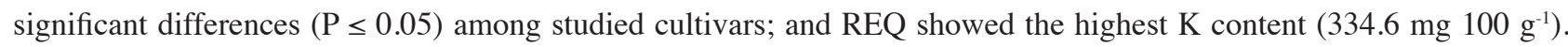
Although Fe and $\mathrm{Zn}$ contents in the three cultivars were lower than other published studies (Lee and Sim, 2018), they were much higher than the regionally popular cereals such as wheat, corn and rice (Nowak et al., 2016). It is known that the chemical and mineral composition of quinoa seeds is significantly affected by geographical areas, $\mathrm{N}$ bioavailability, and genetic background (Miranda et al., 2011).

\section{Analysis of free amino acids}

According to some studies, the content of amino acids in quinoa depends on the region of cultivation and genetic variability of seeds (Miranda et al., 2012; Lee and Sim, 2018). This variation can be explained by the genetic characteristics of the Ecuatorian seeds, that are cultivated in Highland volcanic soils (2500 $\mathrm{m}$ a.s.l.), while that the Mexican quinoa grows at low altitude (950 m a.s.1.) In the studied samples, 18 amino acids were detected, including eight essential (Figure 2). WMxQ accumulated the highest concentration of almost all free amino acids. The most abundant free amino acids in the three quinoa cultivars were arginine, glutamic acid, and alanine. The arginine content in WEQ $\left(6.25 \mathrm{nmol} \mathrm{mg}^{-1}\right)$ was significantly higher than WMxQ (3.09 $\left.\mathrm{nmol} \mathrm{mg}^{-1}\right)$; glutamic acid content showed nonsignificant differences ( $\left.\mathrm{P}>0.05\right)$ among WMxQ, WEQ, and REQ cultivars. Alanine content was similar between WMxQ $\left(3.84 \mathrm{nmol} \mathrm{mg}^{-1}\right)$ and WEQ $\left(3.55 \mathrm{nmol} \mathrm{mg}^{-1}\right)$, while red seeds were low in arginine and alanine contents. Arginine is a critical amino acid for children and adolescents due to its role in stimulating the production and release of growth hormones (Abugoch-James, 2009) and also in production of creatine, a compound involved in the muscle regeneration process (Kreider et al., 2017). The essential amino acids (histidine, lysine, methionine, valine, isoleucine, leucine, phenylalanine, and threonine) represented about $27 \%$ of the total amino acids analyzed. Consistent with other studies (Lee and Sim, 2018), our results confirmed the abundant accumulation of arginine, glutamic acid, alanine, histidine, aspartic acid, glycine, and lysine in all three cultivars. Food consumption with a balanced composition of amino acids may replace amino acids lost in natural biochemical processes, contributing to the prevention of age-related diseases and improving health (Rose, 2019).

Figure 2. Free amino acids profile of three quinoa cultivars.

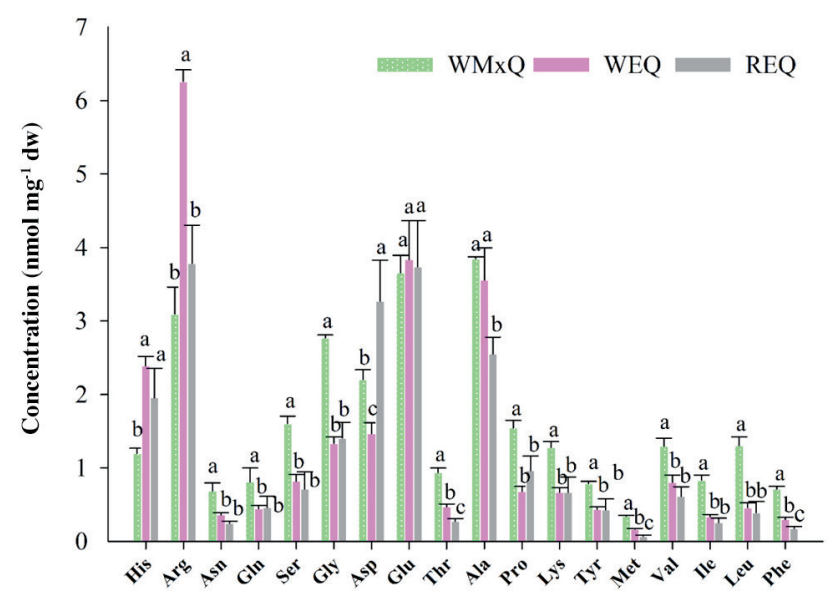

Means \pm standard deviation followed by different letters are significantly different for each aminoacid $(\mathrm{n}=3, \mathrm{P} \leq 0.05)$.

dw: Dry weight; WMxQ: white Mexico quinoa; WEQ: white Ecuador quinoa; REQ: red Ecuador quinoa. 


\section{Fatty acid composition}

The fatty acids profile in the studied quinoa cultivars is displayed in Table 2 . In all three cultivars, unsaturated fatty acids were most predominant (73.6\% to $78.0 \%)$. Linoleic acid was the primary fatty acid ranging from $45.4 \%$ to $53.9 \%$, followed by oleic acid (23.8\% to $28.0 \%$ ). The results evidenced that WMxQ and WEQ contained higher linoleic acid concentration than Peruvian quinoa seeds (30\%) (Pereira et al., 2019). In addition, the content of linoleic acid in quinoas cultivated in WMxQ and WEQ was higher than the reported in peanut, almond, olive, coconut, wheat germ and rice germ oil (Orsavova et al., 2015). Linoleic acid is important in the human diet because it reduces the risk of cardiovascular diseases and the incidence of diabetes type II (Abugoch-James, 2009). The fatty acids composition of seeds in the present study was comparable to those reported for different quinoa varieties cultivated in USA (Wood et al., 1993).

\section{Free and bound phenols and flavonoids content}

The results of total phenolic content (TPC) in free and bound forms are shown in Figure 3A. The TPC is the sum of the free and bound fractions; the free phenolic content in WMxQ was 40.9\% higher than WEQ and showed significant differences $(\mathrm{P} \leq 0.05)$ between cultivars. While, in the bound fraction, WMxQ showed 77.7\% more TPC than WEQ. The highest TPC in WMxQ (2.9 $\left.\mathrm{mg} \mathrm{GAE} \mathrm{g}^{-1} \mathrm{fw}\right)$, with respect to Ecuadorian seeds, can be explained given their genotypic difference in addition to limited irrigation conditions and high temperature exposure, factors that could increase the production of free phenolic compounds (Piovesana et al., 2018). According to Fischer et al. (2013), water restriction during the vegetative cycle and genetic variability of the genotype have a significant effect on the increase of TPC and antioxidant capacity. The free fraction of WMxQ was slightly higher than those reported by Tang et al. (2015) for white seeds (2.2 $\left.\mathrm{mg} \mathrm{GAE} \mathrm{g}^{-1}\right)$. Abderrahim et al. (2015) reported TPC values from 2.5 to $2.7 \mathrm{mg} \mathrm{GAE} \mathrm{g}^{-1}$ for red quinoa seeds, these results were higher than our results. The TPC in WMxQ and WEQ was also slightly lower than obtained from quinoa seeds cultivated in Peru, USA, and Korea (3.4, 4.3 and 4.5 $\mathrm{mg} \mathrm{GAE} \mathrm{g}^{-1}$, respectively) (Lee and Sim, 2018).

Table 2. Fatty acids profile by gas chromatography on quinoa seeds cultivated in different regions.

\begin{tabular}{|c|c|c|c|c|c|c|c|c|c|}
\hline \multirow[b]{2}{*}{ Cultivars } & \multicolumn{4}{|c|}{ Saturated } & \multicolumn{4}{|c|}{ Unsaturated } & \multirow[b]{2}{*}{ NI } \\
\hline & $\begin{array}{l}\text { Palmitic } \\
\text { (C16:0) }\end{array}$ & $\begin{array}{l}\text { Estearic } \\
\text { (C18:0) }\end{array}$ & $\begin{array}{l}\text { Araquidic } \\
\text { (C20:0) }\end{array}$ & Total & $\begin{array}{l}\text { Palmitoleic } \\
\text { (C16:1) }\end{array}$ & $\begin{array}{l}\text { Oleic } \\
\text { (C18:1) }\end{array}$ & $\begin{array}{l}\text { Linoleic } \\
\text { (C18:2) }\end{array}$ & Total & \\
\hline & \multicolumn{4}{|c|}{$\longrightarrow$ Area $\longrightarrow$} & \multicolumn{4}{|c|}{$\longrightarrow$ Area $\longrightarrow$} & $\%$ Area \\
\hline WMxQ & 10.02 & 0.56 & 0.40 & 10.99 & 0.22 & 23.81 & 53.99 & 78.02 & 10.99 \\
\hline WEQ & 9.65 & 0.62 & 0.43 & 10.70 & 0.19 & 25.76 & 52.13 & 78.08 & 11.22 \\
\hline REQ & 10.32 & 0.72 & 0.53 & 11.57 & 0.20 & 28.04 & 45.42 & 73.66 & 14.77 \\
\hline
\end{tabular}

NI: Not identified; WMQ: White Mexico quinoa; WEQ: white Ecuador quinoa; REQ: red Ecuador quinoa.

Figure 3. Free and bound phenols (A) and flavonoids (B) content of three quinoa cultivars.
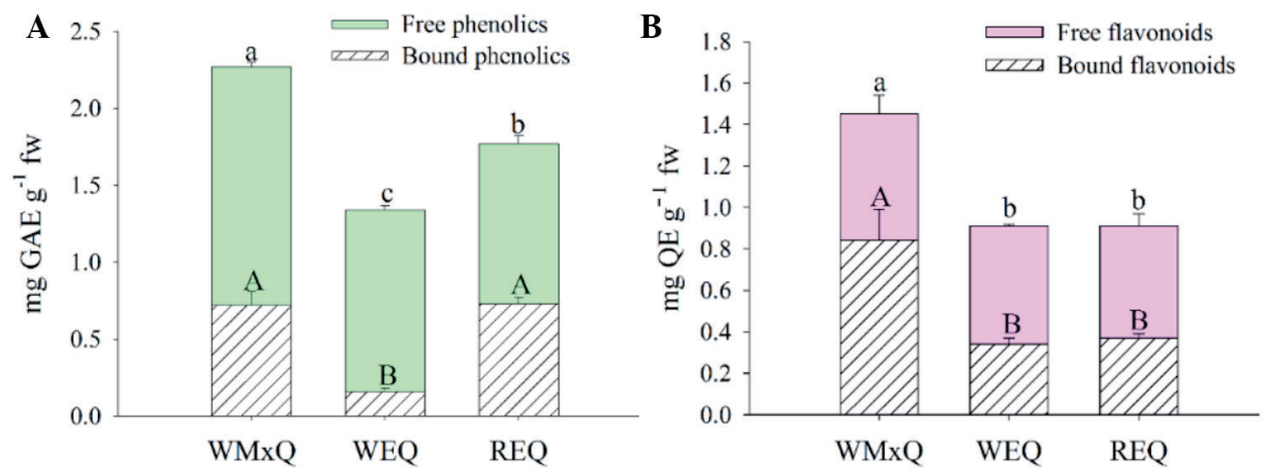

Means \pm standard deviation followed by different letters are significantly different in free or bound compounds $(\mathrm{n}=3, \mathrm{P} \leq 0.05)$.

GAE: Gallic acid equivalent; fw: fresh weight; QE: quercetin equivalent; WMxQ: white Mexico quinoa; WEQ: white Ecuador quinoa; REQ: red Ecuador quinoa. 
The most abundant flavonoids in quinoa seeds are flavonols like quercetin, myricetin, and kaempferol derivatives. Quercetin has the highest antioxidant capacity, therefore provides multiple benefits to human health (Tang et al., 2015). Free flavonoids content in $\mathrm{WMxQ}\left(1.45 \mathrm{mg} \mathrm{QE} \mathrm{g}^{-1} \mathrm{fw}\right)$ was significantly higher $(\mathrm{P} \leq 0.05)$ than WEQ (0.91 $\mathrm{mg} \mathrm{QE} \mathrm{g}^{-1} \mathrm{fw}$ ), which is equivalent to $37.2 \%$ more flavonoids regarding the cultivars from Ecuador (Figure 3B). Regarding bound flavonoids, WMxQ exceeded by 59.5\% and 55.9\% to WEQ and REQ, respectively. The TFC was the highest in the soluble phenolic fraction that in the extract by acid-hydrolysis. The free flavonoid values in WMxQ and WEQ were slightly lower than those reported by Lee and Sim (2018) for white quinoa seeds (between 1.4 and $1.9 \mathrm{mg} \mathrm{QE} \mathrm{g}^{-1}$ ). The free flavonoid content in REQ was comparable with the values from 0.81 to $1.34 \mathrm{mg} \mathrm{QE} \mathrm{g}^{-1}$ presented by Abderrahim et al. (2015). It is important to consider that the variation of polyphenols in quinoa seeds could be related to crop conditions, varieties, and environmental factors (Miranda et al., 2011).

\section{Content of free and bound betalains in red quinoa}

Betalains are the pigments involved in the different colors of quinoa seeds, these pigments are divided into two groups, betacyanins $(\mathrm{Bc})$ and betaxanthins $(\mathrm{Bx})$. Total betalain content is the sum of $\mathrm{Bc}$ and $\mathrm{Bx}$ present in the sample and was determined in free and bound fraction of red seeds extract. Betalains were not detected in the free fraction extract; however, in the bound extract betalains, betaxanthins $\left(44.9 \mathrm{mg} 100 \mathrm{~g}^{-1} \mathrm{fw}\right)$ and betacyanins $\left(38.4 \mathrm{mg} 100 \mathrm{~g}^{-1} \mathrm{fw}\right)$ were identified at 435 and $535 \mathrm{~nm}$, respectively. The total betalains content $\left(83.3 \mathrm{mg} 100 \mathrm{~g} \mathrm{~g}^{-1} \mathrm{fw}\right)$ in red quinoa seeds from Ecuador was higher compared with the values reported by $\mathrm{Li}$ et al. (2015) for amaranth seeds from Mexico, Guatemala and Andean region $\left(0.07\right.$ to $\left.0.96 \mathrm{mg} 100 \mathrm{~g}^{-1}\right)$. The $\mathrm{Bc}$ and $\mathrm{Bx}$ contents in the present study were higher than those determined by Abderrahim et al. (2015) for quinoa seeds, these authors used the conventional extraction method with methanol:water (20:80 $\mathrm{v} / \mathrm{v}$, room temperature). On the other hand, Laqui-Vilca et al. (2018) reported values between 70.7 and $89.6 \mathrm{mg}^{100 \mathrm{~g} \mathrm{~g}^{-1}}$ for Bc

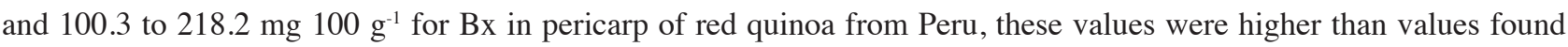
in REQ. The latter article results were obtained mixing $50 \mu \mathrm{g}$ quinoa with water to a final volume of $500 \mu \mathrm{L}$, using the microwave-assisted extraction method. In this study, the total betalains content was extracted by acid-hydrolysis with heating, however, it is important to consider the time and temperature to avoid degradation of pigment. In addition, the results of this study demonstrate that the pigments responsible for the red quinoa seeds are betalains and not anthocyanins as reported by Pásko et al. (2009). The betalains are $\mathrm{N}$ compounds present in color seeds, its variation can be related with the high $\mathrm{N}$ concentration in volcanic origin soils.

\section{Antioxidant capacity}

Figure 4 shows the results of antioxidant capacity (AC) as measured by ABTS, FRAP, and DPPH methods of three quinoa cultivars. The antioxidant capacity in REQ was significantly higher $(\mathrm{P} \leq 0.05)$ than white quinoas in all methods applied, this can be explained by the contribution of betalains to AC. The ABTS values (Figure 4A) in the free and bound phenolic fractions displayed significantly higher $(\mathrm{P} \leq 0.05) \mathrm{AC}$ in WMxQ $\left(1.74 \mathrm{mg} \mathrm{TE} \mathrm{g}^{-1} \mathrm{fw}\right)$ and with respect to WEQ. The FRAP analysis (Figure 4B) showed significant differences $(P \leq 0.05)$ between studied quinoas. WMxQ $\left(1.9 \mathrm{mg} \mathrm{TE} \mathrm{g}^{-1} \mathrm{fw}\right)$ presented $52.7 \%$ more AC than WEQ in the free phenolic fraction. In bound phenolic fraction, WMxQ $\left(0.5 \mathrm{mg} \mathrm{TE} \mathrm{g}^{-1} \mathrm{fw}\right.$ ) showed $80 \%$ more AC than WEQ. The same behavior was observed by the DPPH method (Figure 4C), the $\mathrm{AC}$ in the free phenolic fraction of WMxQ $\left(1.0 \mathrm{mg} \mathrm{TE} \mathrm{g}^{-1} \mathrm{fw}\right)$ was higher than WEQ. Mexican quinoa presented $\mathrm{IC}_{50}$ of $4.55 \mathrm{mg} \mathrm{mL}^{-1}$, which is equivalent to $47.1 \%$ more $\mathrm{AC}$ regarding the white quinoa from Ecuador. However, in the bound phenolic fraction, WMxQ and WEQ showed nonsignificant differences. On the other hand, in the bound phenolic fraction, REQ showed $\mathrm{IC}_{50}$ value $\left(0.784 \mathrm{mg} \mathrm{mL}^{-1} \mathrm{fw}\right)$ lower than white quinoas, which is equivalent to $96.9 \%$ and $97.2 \%$ more $\mathrm{AC}$ for WMxQ and WEQ respectively. Tang et al. (2015) found that the AC was higher (>3000 mg kg-1) in the hydrolysate fraction from red and black quinoas than free fraction, in the present study REQ had the same behavior. The AC obtained in the free phenolic fraction of the studied quinoas was lower than those presented by Pellegrini et al. (2018) for white seeds ( 1.9 to $4.5 \mathrm{mg} \mathrm{TE}^{-1}$ ) and red seeds ( 4.5 to $7.7 \mathrm{mg} \mathrm{TE} \mathrm{g}^{-1}$ ) by the ABTS, FRAP and DPPH methods. Regarding the DPPH results of quinoa seeds, the values in free phenolic fraction were comparable with $\mathrm{IC}_{50}\left(0.46\right.$ and $\left.3.77 \mathrm{mg} \mathrm{mL}^{-1}\right)$ presented by Miranda et al. (2011). The difference in AC with other authors could be explained for the extraction method used, for the type of solvent, and time. The AC is associated with the phenolic content in free or bound forms, these compounds exert biological activities for the benefit of human health. 
Figure 4. Antioxidant capacity by ABTS (A), FRAP (B) and DPPH (C) methods in quinoa cultivated in different regions.

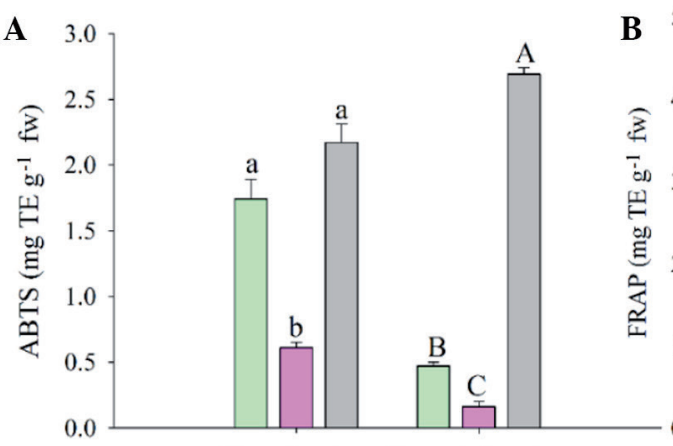

Free fraction Bound fraction

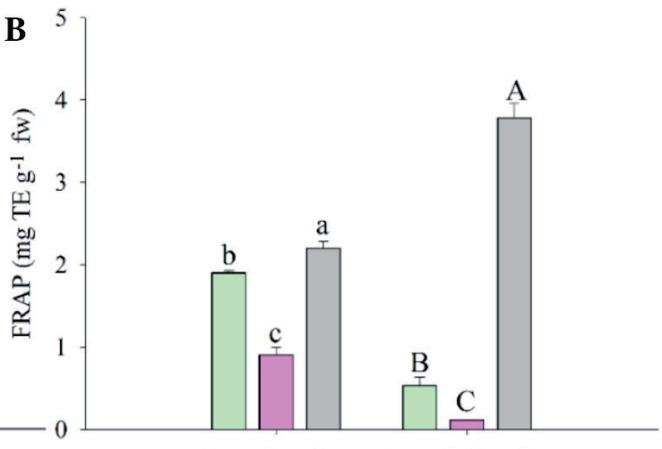

Free fraction Bound fraction

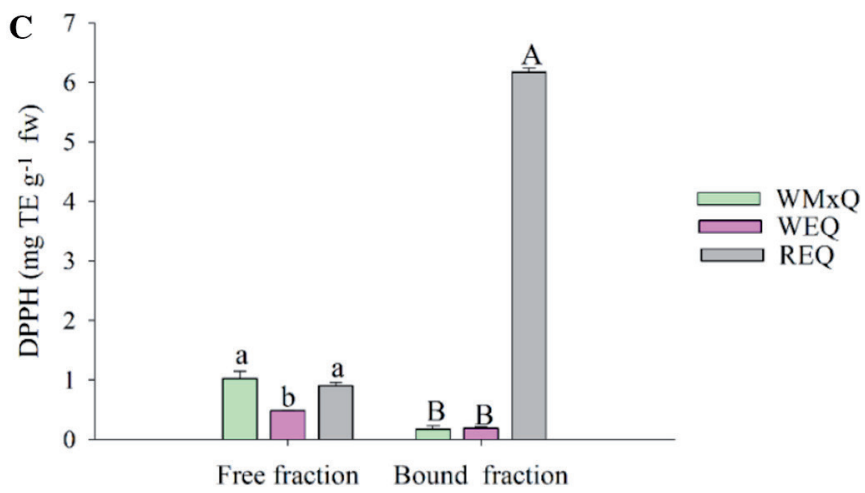

Means \pm standard deviation followed by different letters are significantly different in free or bound compounds $(\mathrm{n}=3, \mathrm{P} \leq 0.05)$. TE: Trolox equivalent; fw: fresh weight; WMxQ: white Mexico quinoa; WEQ: white Ecuador quinoa; REQ: red Ecuador quinoa.

\section{CONCLUSIONS}

In the present study, the nutritional composition showed high contents of fiber, ash, $\mathrm{P}, \mathrm{Ca}, \mathrm{Mg}$ in the seeds of Mexican quinoa, while the seeds of white quinoa from Ecuador accumulated high contents of protein, fats, $\mathrm{Fe}$, $\mathrm{Zn}$, and amino acids such as arginine, histidine, alanine, and glutamic acid. Red quinoa showed higher content of carbohydrates, fiber, and $\mathrm{K}$ than white quinoas. All three studied quinoa cultivars showed presence of all essential amino acids $\left(0.3\right.$ to $\left.1.3 \mathrm{nmol} \mathrm{mg}^{-1}\right)$. The quinoa seeds oil was high in unsaturated fatty acids, mainly linoleic acid (45.4\% to $53.9 \%$ ). Regarding phenolics composition, Mexican quinoa had the highest phenolic content. Betalains were found only in the bound fraction of red quinoa. The acid hydrolysis method increased the extraction of betalains, compared to the assisted-microwave method previously reported. The seeds grown in Mexico showed almost 50\% higher phenolic content than white quinoa seeds. Quinoa seeds adapted in Mexico have an improved nutritional and nutraceutical composition compared to white quinoa seeds from Ecuador.

\section{ACKNOWLEDGEMENTS}

This study was developed by the 21017-EI project from Universidad Autónoma Chapingo. The scholarship of the Magali Anabel Cañarejo-Antamba was supported by CONACYT, México. The authors acknowledge to Experimental Station of Tlaltizapan, CIMMYT, State of Morelos, México and the Ministry of Agriculture and Livestock (MAG), Imbabura Province, Ecuador. 


\section{REFERENCES}

Abderrahim, F., Huanatico, E., Segura, R., Arribas, S., Gonzalez, M.C., and Condezo-Hoyos, L. 2015. Physical features, phenolic compounds, betalains and total antioxidant capacity of coloured quinoa seeds (Chenopodium quinoa Willd.) from Peruvian Altiplano. Food Chemistry 183:83-90. https://doi.org/10.1016/j.foodchem.2015.03.029.

Abugoch-James, L.E.2009. Chapter 1. Quinoa (Chenopodium quinoa Willd.): Composition, chemistry, nutritional and functional properties. p. 1-31. In Taylor, S.L. (ed.) Advances in food and nutrition research. Vol. 58. Academic Press, Cambridge, Massachusetts, USA. https://doi.org/10.1016/S1043-4526(09)58001-1.

AOAC. 1998. Official methodos of analysis of AOAC International. 16 ${ }^{\text {th }}$ ed. Association of Official Analytical Chemists (AOAC) International, Gaithersburg, Maryland, USA.

Arslanoglu, F., Aytac, S., and Oner, E.K. 2011. Effect of genotype and environment interaction on oil and protein content of soybean (Glycine max (L.) Merrill) seed. African Journal of Biotechnology 10(80):18409-18417. https://doi.org/10.5897/AJB10.1879.

Benzie, I.F.F., and Strain, J.J. 1996. The ferric reducing ability of plasma (FRAP) as a measure of "antioxidant power": The FRAP assay. Analytical Biochemistry 239(1):70-76. https://doi.org/10.1006/abio.1996.0292.

Castellanos-Santiago, E., and Yahia, E.M. 2008. Identification and quantification of betalains from the fruits of 10 Mexican prickly pear cultivars by high-performance liquid chromatography and electrospray ionization mass spectrometry. Agricultural and Food Chemistry 56:5758-5764.

Ceyhun, A., and Sanlier, N. 2019. A new generation plant for the conventional cuisine: Quinoa (Chenopodium quinoa Willd.) Trends in Food Science \& Technology 86:51-58. https://doi.org/10.1016/j.tifs.2019.02.039.

Chang, C.C., Yang, M.H., Wen, H.M., and Chern, J.C. 2002. Estimation of total flavonoid content in propolis by two complementary colometric methods. Journal of Food and Drug Analysis 10:178-182.

Cheng, Z., Moore, J., and Yu, L. 2006. High-throughput relative DPPH radical scavenging capacity assay. Agricultural and Food Chemistry 54(1):7429-7436.

Fischer, S., Wilckens, R., Jara, J., and Aranda, M. 2013. Variation in antioxidant capacity of quinoa (Chenopodium quinoa Will.) subjected to drought stress. Industrial Crops and Products 46:341-349. https://doi.org/10.1016/j.indcrop.2013.01.037.

García-Parra, M., Zurita-Silva, A., Stechauner-Rohringer, R., Roa-Acosta, D., and Jacobsen, S.E. 2020. Quinoa (Chenopodium quinoa Willd.) and its relationship with agroclimatic characteristics: A Colombian perspective. Chilean Journal of Agricultural Research 80:290-302. https://doi.org/10.4067/S0718-58392020000200290.

Gavlak, R., Horneck, R., Miller, R.O., and Kotuby-Amacher, J. 2013. Soil, plant and water reference methods for the Western Region. $4^{\text {th }}$ ed. Colorado State University, Fort Collins, Colorado, USA.

Hernández-Ledesma, B. 2019. Quinoa (Chenopodium quinoa Willd.) as source of bioactive compounds: A review. Bioactive Compounds in Health and Disease 2(3):27-47. https://doi.org/10.31989/bchd.v2i3.556.

Hernández-Rodríguez, G., Espinosa-Solares, T., Hernández-Eugenio, G., Villa-García, M., Reyes-Trejo, B., and GuerraRamírez, D. 2016. Influence of polar solutions on the extraction of phenolic compounds from capulín fruits (Prunus serotina). Mexican Chemical Society 60:73-78.

Huygens, D., Boeckx, P., Templer, P., Paulino, L., Van Cleemput, O., Oyarzún, C., et al. 2008. Mechanisms for retention of bioavailable nitrogen in volcanic rainforest soils. Nature Geoscience 1(8):543-548. https://doi.org/10.1038/ngeo252.

Joshi, V., Laubengayer, K.M., Schauer, N., Fernie, A.R., and Jander, G. 2006. Two Arabidopsis threonine aldolases are nonredundant and compete with threonine deaminase for a common substrate pool. The Plant Cell 18(12):3565-3575. https://doi.org/10.1105/tpc.106.044958.

Kreider, R.B., Kalman, D.S., Antonio, J., Ziegenfuss, T.N., Wildman, R., Collins, R., et al. 2017. International Society of Sports Nutrition position stand: Safety and efficacy of creatine supplementation in exercise, sport, and medicine. Journal of the International Society of Sports Nutrition 14(1):1-18. https://doi.org/10.1186/s12970-017-0173-z.

Laqui-Vilca, C., Aguilar-Tuesta, S., Mamani-Navarro, W., Montaño-Bustamante, J., and Condezo-Hoyos, L. 2018. Ultrasoundassisted optimal extraction and thermal stability of betalains from colored quinoa (Chenopodium quinoa Willd) hulls. Industrial Crops \& Products 111:606-614. https://doi.org/10.1016/j.indcrop.2017.11.034.

Lee, M., and Sim, K.H. 2018. Nutritional value and the kaempferol and quercetin contents of quinoa (Chenopodium quinoa Willd.) from different regions. Foos Science and Technology 50(6):680-687.

Li, H., Deng, Z., Liu, R., Zhu, H., Draves, J., Marcone, M., et al. 2015. Characterization of phenolics, betacyanins and antioxidant activities of the seed, leaf, sprout, flower and stalk extracts of three Amaranthus species. Journal of Food Composition and Analysis 37:75-81. https://doi.org/10.1016/j.jfca.2014.09.003.

López-Yerena, A., Guerra-Ramírez, D., Jácome-Rincón, J., Espinosa-Solares, T., Reyes-Trejo, B., Famiani, F., et al. 2018. Initial evaluation of fruit of accessions of Persea schiedeana Nees for nutritional value, quality and oil extraction. Food Chemistry 245:879-884. https://doi.org/10.1016/j.foodchem.2017.11.088.

Maradini Filho, A.M.M., Pirozi, M.R., Borges, J.T.D.S., Pinheiro Sant'Ana, H.M., Chaves, J.B.P., and Coimbra, J.S. 2017. Quinoa: Nutritional, functional, and antinutritional aspects. Critical Reviews in Food Science and Nutrition 57(8):16181630. https://doi.org/10.1080/10408398.2014.1001811. 
McGuire, R.G. 1992. Reporting of objective color measurements. HortScience 27(12):1254-1255.

Miranda, M., Vega-Gálvez, A., Martinez, E., López, J., Rodríguez, M.J., et al. 2012. Genetic diversity and comparison of physicochemical and nutritional characteristics of six quinoa (Chenopodium quinoa willd.) genotypes cultivated in Chile. Food Science and Technology 32(4):835-843. https://doi.org/10.1590/s0101-20612012005000114.

Miranda, M., Vega-Gálvez, A., Uribe, E., López, J., Martínez, E., Rodríguez, M.J., et al. 2011. Physico-chemical analysis, antioxidant capacity and vitamins of six ecotypes of Chilean quinoa (Chenopodium quinoa Willd). Procedia Food Science 1:1439-1446. https://doi.org/10.1016/j.profoo.2011.09.213.

Nowak, V., Du, J., and Charrondière, U.R. 2016. Assessment of the nutritional composition of quinoa (Chenopodium quinoa Willd.) Food Chemistry 193:47-54. https://doi.org/10.1016/j.foodchem.2015.02.111.

Orsavova, J., Misurcova, L., Ambrozova, J.V., and Vicha, R. 2015. Fatty acids composition of vegetable oils and its contribution to dietary energy intake and dependence of cardiovascular mortality on dietary intake of fatty acids. Molecular Science 16(6):12871-12890. https://doi.org/10.3390/ijms160612871.

Pásko, P., Barton, H., Zagrodzki, P., Gorinstein, S., Fołta, M., and Zachwieja, Z. 2009. Anthocyanins, total polyphenols and antioxidant activity in amaranth and quinoa seeds and sprouts during their growth. Food Chemistry 115:994-998. https://doi.org/10.1016/j.foodchem.2009.01.037.

Pellegrini, M., Lucas-Gonzales, R., Ricci, A., Fontecha, J., Fernández-López, J., Pérez-Álvarez, J., et al. 2018. Chemical, fatty acid, polyphenolic profile, techno-functional and antioxidant properties of flours obtained from quinoa (Chenopodium quinoa Willd) seeds. Industrial Crops and Products 111:38-46. https://doi.org/10.1016/j.indcrop.2017.10.006.

Pereira, E., Encina-Zelada, C., Barros, L., Gonzales-Barron, U., Cadavez, V., and Ferreira, I.C.F.R. 2019. Chemical and nutritional characterization of Chenopodium quinoa Willd (quinoa) grains: A good alternative to nutritious food. Food Chemistry 280:110-114. https://doi.org/10.1016/j.foodchem.2018.12.068.

Piovesana, S., Capriotti, A.L., Cavaliere, C., La Barbera, G., Montone, C.M., Zenezini Chiozzi, R., et al. 2018. Recent trends and analytical challenges in plant bioactive peptide separation, identification and validation. Analytical and Bioanalytical Chemistry 410:3425-3444. https://doi.org/10.1007/s00216-018-0852-x.

Re, R., Pellegrini, N., Proteggente, A., Pannala, A., Yang, M., and Rice-Evans, C. 1999. Antioxidant activity applying an improved ABTS radical cation decolorization assay. Free Radical Biology and Medicine 26(9-10):1231-1237. https://doi.org/10.1016/j.indcrop.2017.04.056.

Rojas, W., Alandia, G., Irigoyen, J., Blajos, J., y Santivañez, T. 2011. La quinua: Cultivo milenario para contribuir a la seguridad alimentaria mundial. Oficina Regional para America Latina y El Caribe, FAO, Santiago, Chile. https://doi.org/10.1016/j.jaridenv.2009.03.010.

Rose, A. 2019. Amino acid nutrition and metabolism in health and disease. Nutrients 11(2):1-4. https://doi.org/10.3109/016770 63.2011.647143.

Shetty, M.J., and Geethalekshmi, P. 2017. Natural pigments as potential food colourants: A review. Trends in Biosciences 10(21):4057-4064.

Sobota, A., Swieca, M., Gesinski, K., Wirkijowska, A., and Bochnak, J. 2020. Yellow-coated quinoa (Chenopodium quinoa Willd) - physicochemical, nutritional, and antioxidant properties. Journal of the Science of Food and Agriculture 100(5):20352042. https://doi.org/10.1002/jsfa.10222.

Tang, Y., Li, X., Zhang, B., Chen, P.X., Liu, R., and Tsao, R. 2015. Characterisation of phenolics, betanins and antioxidant activities in seeds of three Chenopodium quinoa Willd. genotypes. Food Chemistry 166:380-388. https://doi.org/10.1016/j.foodchem.2014.06.018.

Tang, Y., and Tsao, R. 2017. Phytochemicals in quinoa and amaranth grains and their antioxidant, anti-inflammatory, and potential health beneficial effects: a review. Molecular Nutrition and Food Research 61(7):1-16. https://doi.org/10.1002/ mnfr.201600767.

Vega-Gálvez, A., Miranda, M., Vergara, J., Uribe, E., Puente, L., and Martínez, E.A. 2010. Nutrition facts and functional potential of quinoa (Chenopodium quinoa willd.), an ancient Andean grain: A review. Journal of the Science of Food and Agriculture 90(15):2541-2547. https://doi.org/10.1002/jsfa.4158.

Vilcacundo, R., and Hernández-Ledesma, B. 2017. Nutritional and biological value of quinoa (Chenopodium quinoa Willd.) Current Opinion in Food Science 14:1-6. https://doi.org/10.1016/j.cofs.2016.11.007.

Wood, S.G., Lawson, L.D., Fairbanks, D.J., Robison, L.R., and Andersen, W.R. 1993. Seed lipid content and fatty acid composition of three quinoa cultivars. Journal of Food Composition and Analysis 6(1):41-44. https://doi.org/10.1006/ jfca.1993.1005. 